PREPARED FOR THE U.S. DEPARTMENT OF ENERGY, UNDER CONTRACT DE-AC02-76CH03073

PPPL-3582

PPPL-3582

UC-70

Physics Regimes in the Fusion Ingnition Research Experiment (FIRE)

D.M. Meade, S.C. Jardin, C.E. Kessel, M.A. Ulrickson, J.H. Schultz, P.H. Rutherford, J.A. Schmidt, J.C. Wesley, K.M. Young, N.A. Uckan, R.J. Thome, P. Heitzenroeder, B.E. Nelson, and C.C. Baker

June 2001
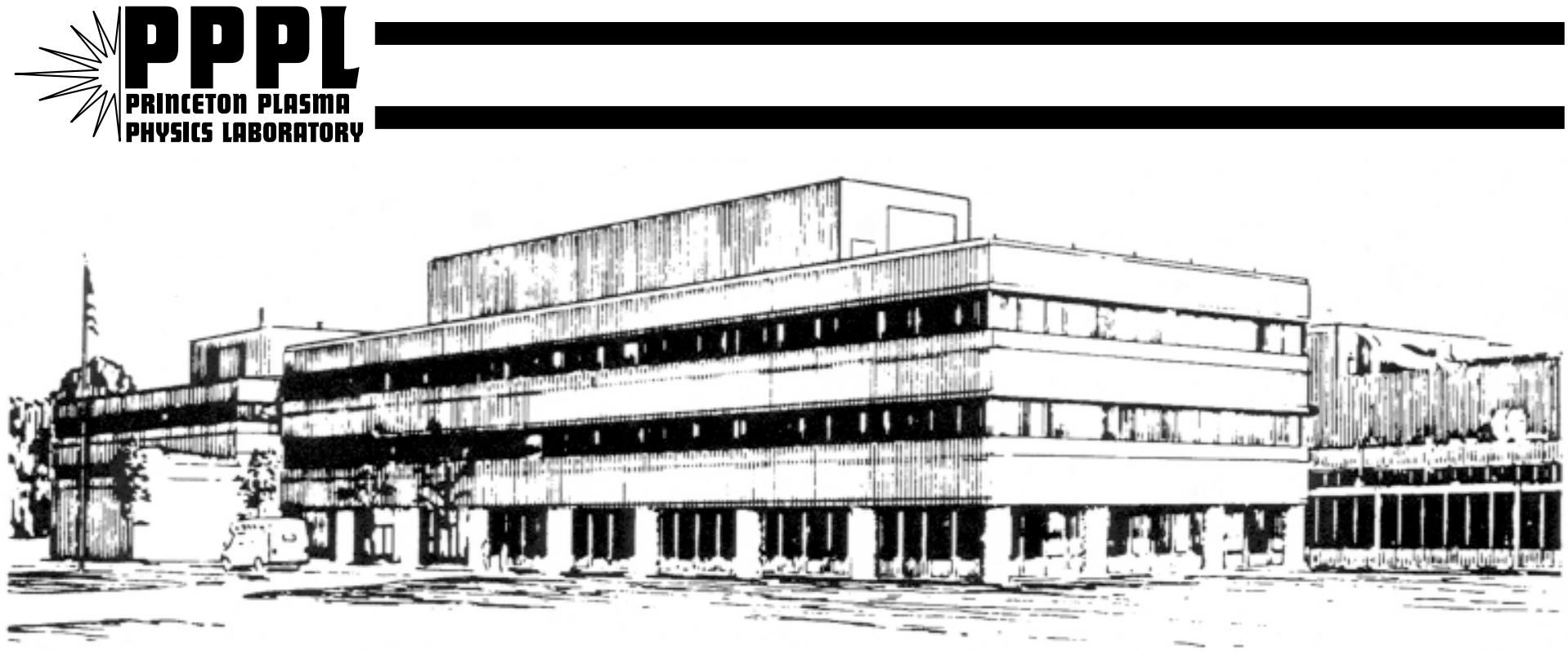

PRINCETON PLASMA PHYSICS LABORATORY PRINCETON UNIVERSITY, PRINCETON, NEW JERSEY 


\section{PPPL Reports Disclaimer}

This report was prepared as an account of work sponsored by an agency of the United States Government. Neither the United States Government nor any agency thereof, nor any of their employees, makes any warranty, express or implied, or assumes any legal liability or responsibility for the accuracy, completeness, or usefulness of any information, apparatus, product, or process disclosed, or represents that its use would not infringe privately owned rights. Reference herein to any specific commercial product, process, or service by trade name, trademark, manufacturer, or otherwise, does not necessarily constitute or imply its endorsement, recommendation, or favoring by the United States Government or any agency thereof. The views and opinions of authors expressed herein do not necessarily state or reflect those of the United States Government or any agency thereof.

\section{Availability}

This report is posted on the U.S. Department of Energy's Princeton Plasma Physics Laboratory Publications and Reports web site in Calendar Year 2001. The home page for PPPL Reports and Publications is: http://www.pppl.gov/pub_report/

DOE and DOE Contractors can obtain copies of this report from:

U.S. Department of Energy

Office of Scientific and Technical Information

DOE Technical Information Services (DTIS)

P.O. Box 62

Oak Ridge, TN 37831

Telephone: (865) 576-8401

Fax: (865) 576-5728

Email: reports@adonis.osti.gov

This report is available to the general public from:

National Technical Information Service

U.S. Department of Commerce

5285 Port Royal Road

Springfield, VA 22161

Telephone: 1-800-553-6847 or

(703) 605-6000

Fax: (703) 321-8547

Internet: http://www.ntis.gov/ordering.htm 


\title{
Physics Regimes in the Fusion Ignition Research Experiment (FIRE)
}

\author{
D. M. Meade ${ }^{1}$, S. C. Jardin ${ }^{1}$, C. E. Kessel ${ }^{1}$, M. A. Ulrickson ${ }^{2}$, J. H. Schultz ${ }^{5}$, \\ P. H. Rutherford ${ }^{1}$, J. A. Schmidt ${ }^{1}$, J. C. Wesley ${ }^{4}$, K. M. Young ${ }^{1}$, N. A. Uckan ${ }^{5}$, \\ R. J. Thome ${ }^{4}$, P. Heitzenroeder ${ }^{1}$, B. E. Nelson ${ }^{5}$, and C. C. Baker ${ }^{6}$ \\ ${ }^{1}$ Princeton Plasma Physics Laboratory, Princeton, NJ 08543, USA \\ ${ }^{2}$ Sandia National Laboratory, Albuquerque, NM 87185, USA \\ ${ }^{3}$ Massachusetts Institute of Technology, Cambridge, MA 02139, USA \\ ${ }^{4}$ General Atomics, San Diego, CA 92186, USA \\ ${ }^{5}$ Oak Ridge National Laboratory, Oak Ridge, TN 37831, USA \\ ${ }^{6}$ University of California at San Diego, San Diego, CA 92093, USA
}

\section{Introduction}

Burning plasma science is recognized widely as the next frontier in fusion research. FIRE [1, 2 ] is a design study of a next step burning plasma experiment with the goal of developing a concept for an experimental facility to explore and understand the strong non-linear coupling among confinement, MHD self-heating, stability, edge physics and wave-particle interactions that is fundamental to fusion plasma behavior. This will require plasmas dominated by alpha heating $(\mathrm{Q} \geq 5)$ that are sustained for a duration comparable to characteristic plasma time scales $\left(\geq 10 \tau_{\mathrm{E}}, \sim 4 \tau_{\mathrm{He}}, \sim 2 \tau_{\text {skin }}\right.$ ). The work reported here has been undertaken with the objective of finding the minimum size (cost) device to achieve these physics goals.

\section{General Physics Requirements for FIRE}

The first goal of FIRE is to carry out burning plasma experiments to address confinement, MHD stability, fast alpha physics and alpha heating and edge plasma issues expected in fusion reactor scale plasmas. For these experiments alpha heating must dominate the plasma dynamics, therefore $f_{\alpha}$, the fraction of plasma heating due to alpha particles, must be $\geq 50 \%$. This in turn requires that the minimum $\mathrm{Q}=\mathrm{P}_{\text {fusion }} / \mathrm{P}_{\text {ext. heat }} \geq 5$. The goal for the design is to achieve $\mathrm{Q} \approx 10$, with ignition not precluded under optimistic physics.

FIRE is also being designed to study burning plasmas in advanced configurations in a later phase as an extension of the existing advanced tokamak program. For these experiments, it will be desirable to study regimes that are bootstrap current dominated, $\mathrm{f}_{\mathrm{bs}} \geq 50 \%\left(\beta_{\mathrm{N}} \sim 2.6\right)$ with the possibility of exploring $f_{b s}$ up to $75 \%\left(\beta_{\mathrm{N}} \sim 3.6\right)$. These regimes will require strong plasma shaping and stabilization of the $\mathrm{n}=1$ kink by a conducting first wall or feedback.

The pulse duration is a very important requirement for these experiments and should be specified in terms of the natural plasma time scales. The goal for FIRE pulse duration is: $>10 \tau_{\mathrm{E}}$ for pressure profile evolution, $>4 \tau_{\mathrm{He}}$ for alpha ash transport and burn control, and $\sim 2 \tau_{\text {skin }}$ for plasma current profile evolution in advanced regimes.

\section{Parametric Studies of Burning Plasma Experiments}

A system study was undertaken to find the minimum size (current) burning plasma to access the physics requirements discussed above. This study was specialized for inductively-driven tokamaks with TF and PF coils that are pre-cooled to $\mathrm{LN}_{2}$ temperature and then heated adiabatically during the pulse. The system code includes constraints for stress, resistive and 
nuclear heating of the coils and volt-sec requirements. The geometry can be chosen to have TF and PF coils unlinked as in FIRE or linked as in low aspect ratio tokamaks (ST). The code optimizes the allocation of the space in the inner coil stack between the ohmic solenoid and the wedged TF coil. The confinement is taken to be H-mode with ITER98 (y,2) scaling. For these studies, the code varied the major radius $(\mathrm{R})$ and aspect ratio $(\mathrm{A})$ with $\mathrm{H}(\mathrm{y}, 2)=1.0$, $\beta_{\mathrm{N}},=1.5, \kappa_{95}=1.8$ and $\mathrm{q}_{95}=3.1$ to obtain plasmas with $\mathrm{Q} \sim 10$ and $20 \mathrm{~s}$ burn time $(\sim 1.7$ $\left.\tau_{\text {skin }}\right)$. For these constraints, the smallest size device to achieve the burning plasma requirements for a cryogenically-cooled inductively driven tokamak with unlinked TF/PF coils has a shallow minimum around $\mathrm{A} \approx 3.3, \mathrm{~B} \approx 9 \mathrm{~T}$ and $\mathrm{R} \approx 2 \mathrm{~m}$ as shown in Fig. 1a.

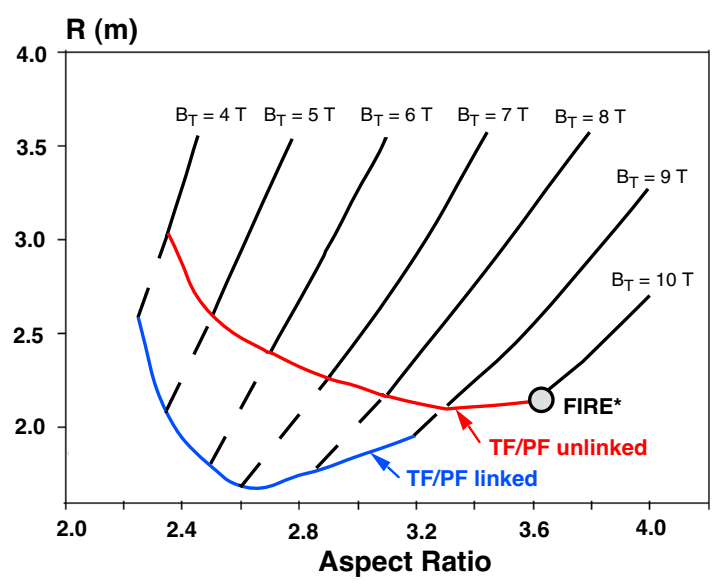

Fig. Ia Major radius versus A

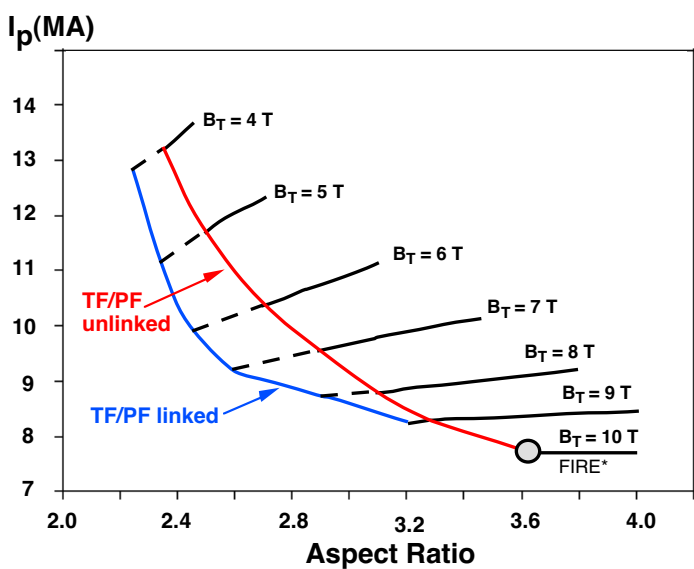

Fig. $1 b$ Plasma current versus A.

The smallest plasma current, which is important for AT optimization, occurs at slightly larger $\mathrm{A}, \approx 3.6$. This illustrates the effect of requiring a longer burn time, which increases the aspect ratio somewhat above previous design optimizations. In the optimization studies carried out using another system code, FIRESALE, with slightly different constraints, the optimum aspect ratio was found to be 3.8. A study of wedged $\mathrm{TF}(\mathrm{BeCu})$ or bucked and wedged $\mathrm{TF}(\mathrm{OFHC})$ coils was carried out using FIRESALE. Two design points FIRE* and FIRE $B / W$ with equivalent physics $\left(\mathrm{Q}=10\right.$ and a burn time of $\left.\approx 2 \tau_{\text {skin }}\right)$ have been identified for further engineering analysis. FIRE options being analyzed are summarized in Table I.

\begin{tabular}{|l|c|c|c|c|c|c|c|c|c|c|}
\hline Table I & $\begin{array}{c}\mathrm{B}_{\mathrm{T}} \\
(\mathrm{T})\end{array}$ & $\begin{array}{c}\mathrm{TF} \\
\text { core }\end{array}$ & $\begin{array}{c}\mathrm{I}_{\mathrm{p}} \\
(\mathrm{MA})\end{array}$ & $\mathrm{ME}$ & $\begin{array}{c}\mathrm{R} \\
(\mathrm{m})\end{array}$ & $\mathrm{A}$ & $\mathrm{Q}$ & $\begin{array}{c}\tau_{\text {pulse }} \\
(\mathrm{s})\end{array}$ & $\begin{array}{c}\tau_{\text {pulse }} \\
\left(\tau_{\text {skin }}\right)\end{array}$ & $\begin{array}{c}\mathrm{P}_{\text {fusion }} \\
(\mathrm{MW})\end{array}$ \\
\hline Baseline & 10 & $\mathrm{BeCu}$ & 6.44 & 1.5 & 2.0 & 3.8 & 5 & 18.5 & 1.5 & 200 \\
\hline Base Hi B & 12 & $\mathrm{BeCu}$ & 7.7 & 1.1 & 2.0 & 3.8 & 20 & 12 & 1.0 & 220 \\
\hline FIRE* & 10 & $\mathrm{BeCu}$ & 7.7 & 1.3 & 2.14 & 3.6 & 10 & 20 & 1.7 & 150 \\
\hline FIRE B/W & 11.5 & OFHC & 6.85 & 1.0 & 1.86 & 3.8 & 10 & 16 & 1.7 & 150 \\
\hline
\end{tabular}

All cases assume $\mathrm{H}(\mathrm{y}, 2)=1.1, \tau_{\mathrm{He}} / \tau_{\mathrm{E}}=5, \mathrm{n} / \mathrm{n}_{\mathrm{GW}} \approx 0.7, \mathrm{n}(0) /\langle\mathrm{n}\rangle=1.2$ and $3 \%$ Be. TF core refers to the conductor material in the inner leg of the TF coil. The engineering margin, ME, $=$ allowable stress/calculated stress.

\section{Plasma Performance Projections}

The burning plasma performance of FIRE is projected using guidelines based on scaling from existing experiments similar to those employed by ITER. The initial studies on the FIRE baseline [1] were based on the confinement scaling (ITER98 IPB(y,1)) used in the ITER-EDA. Under these assumptions, a plasma current of 6.44 MA with modestly peaked density profiles was sufficient to attain $Q \approx 10$ with a pulse length of 20 s $\left(\approx 2 \tau_{\text {skin }}\right)$. The ITER-EDA guidelines also required fusion powers $\sim 200 \mathrm{MW}$ to exceed the H-mode power 
threshold. ITER-FEAT adopted revised design guidelines with confinement scaling (ITER98-IPB $(\mathrm{y}, 2)$ ) that was about $20 \%$ lower and an H-Mode power threshold that was a factor of $\approx 2$ lower than the previous guidelines. Recent 0 -D confinement projections for FIRE have also adopted the ITER-FEAT design guidelines with small changes. The FIRE operating range is well matched to the existing density range relative to the Greenwald density [1], and in this respect FIRE operates at low normalized density. JET operates with normalized parameters closest to those anticipated in FIRE. A search of JET H-mode data in DB4 for FIRE-like discharges $\left(\beta_{\mathrm{N}}>1.7, \kappa_{95}>1.7,2.5<\mathrm{q}_{95}<3.5\right.$ and $\left.\mathrm{Z}_{\text {eff }}<2\right)$ yields average values of $\langle\mathrm{H}(\mathrm{y}, 2)\rangle \approx 1.1$ and $\langle\mathrm{n}(0) /\langle\mathrm{n}\rangle\rangle \approx 1.2$ for data points ranging between $0.3<\mathrm{n} / \mathrm{n}_{\mathrm{GW}}$ $<0.8$. FIRE assumes $3 \% \mathrm{Be}$, no high $\mathrm{Z}$ and $\mathrm{He}$ ash determined self consistently with $\tau_{\mathrm{He}}=5$ $\tau_{\mathrm{E}}$. These assumptions yield a $\mathrm{Z}_{\text {eff }} \approx 1.4$ for FIRE. The calculations of $\mathrm{Q}$ versus $\mathrm{H}$ mode multiplier are shown in Fig. 2 for possible FIRE design points. The initial FIRE baseline would achieve $\mathrm{Q} \geq 5$ for FIRE-like JET confinement, and the $12 \mathrm{~T}$ FIRE would attain $\mathrm{Q} \geq 20$

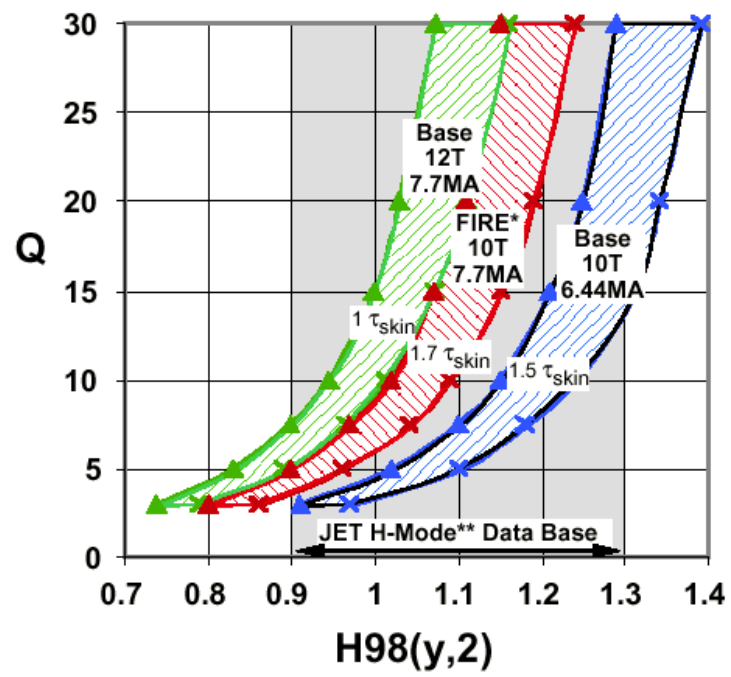

Fig. 2 Fusion Gain for FIRE Options

\begin{tabular}{|l|c|}
\hline $\mathrm{R}(\mathrm{m}), \mathrm{a}(\mathrm{m})$ & $2.14,0.595$ \\
\hline$\kappa_{\mathrm{x}}, \kappa_{\mathrm{a}}$ & $2.0,1.81$ \\
\hline$\delta_{\mathrm{x}}, \delta_{95}$ & $0.7, \approx 0.4$ \\
\hline $\mathrm{q}_{95}$ & $>3$ \\
\hline $\mathrm{B}_{\mathrm{t}}\left(\mathrm{R}_{\mathrm{o}}\right)(\mathrm{T}), \mathrm{I}_{\mathrm{p}}(\mathrm{MA})$ & $10,7.7$ \\
\hline $\mathrm{Q}=\mathrm{P}_{\text {fusion }} /\left(\mathrm{P}_{\mathrm{aux}}+\mathrm{P}_{\mathrm{OH}}\right)$ & 10 \\
\hline $\mathrm{H} 98(\mathrm{y}, 2)$ & 1.1 \\
\hline$\beta_{\mathrm{N}}$ & 1.81 \\
\hline $\mathrm{P}_{\text {loss }} / \mathrm{P}_{\mathrm{LH}}$ & 1.3 \\
\hline $\mathrm{Z}_{\mathrm{eff}}\left(3 \% \mathrm{Be}+\mathrm{He}\left(5 \tau_{\mathrm{E}}\right)\right)$ & 1.4 \\
\hline $\mathrm{R} \nabla \beta_{\alpha}(\%)$ & 3.8 \\
\hline
\end{tabular}

Table II. FIRE*, $Q=10$ Parameters

although for a shorter burn time. A more optimal point is FIRE* (Table II), which with a small increase in size, is projected to achieve $\mathrm{Q} \geq 10$ with $\beta_{\mathrm{N}}<2$ and pulse lengths $\approx 2 \tau_{\text {skin }}$.

The $11 / 2$ D tokamak simulation code (TSC) was used to model the profile and time evolution of FIRE discharges with parameters similar to those analyzed using the 0-D models. An example for FIRE* is shown in Fig. 3. This case had H98 $(y, 2)=1.1$, $\mathrm{n}(0) /\langle\mathrm{n}\rangle=1.2, \mathrm{n} / \mathrm{n}_{\mathrm{GW}}=0.67$ and $\mathrm{Z}_{\mathrm{eff}}=$ 1.4 and indicates that alpha-dominated plasmas can be sustained for $>20 \tau_{\mathrm{E}}$, $>4 \tau_{\mathrm{He}}$ and $\sim 1.7 \tau_{\text {skin. }}$. Neoclassical tearing modes (NTMs) pose a potential threat to the achievement of the required $\beta_{\mathrm{N}}$ values in tokamak burning-plasma experiments such as FIRE, since the polarization-current stabilization model predicts that the critical $\beta_{\mathrm{N}}$ for their onset scales like $\rho_{\mathrm{i}}^{*}$. The value of $\rho_{\mathrm{i}}^{*}$ in FIRE is intermediate between that in presentday tokamaks such as JET and that in

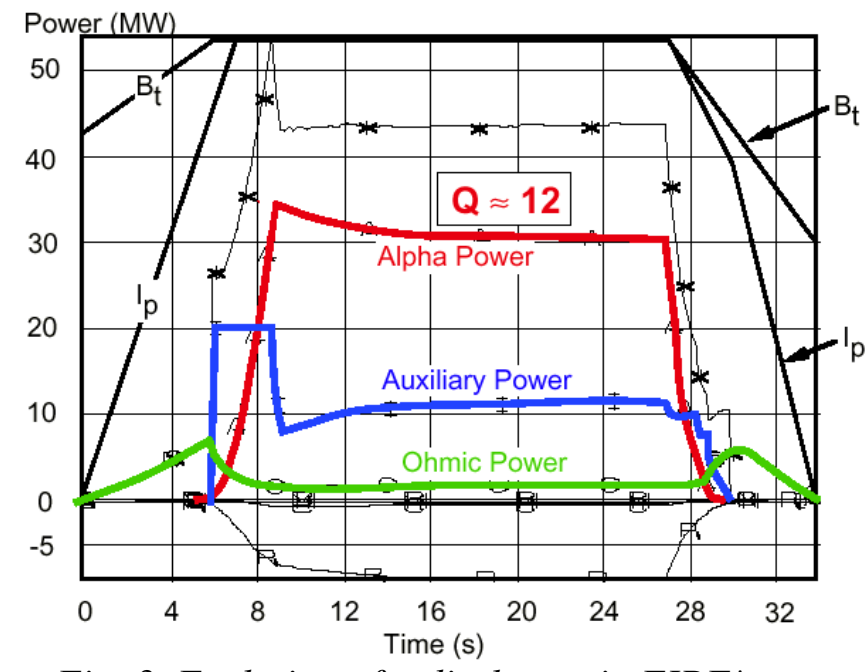

Fig. 3 Evolution of a discharge in FIRE*. 
ITER-FEAT, and NTMs might arise in FIRE for the reference values of $\beta_{\mathrm{N}}(1.5-2.0)$. For this reason, NTM suppression by feedback-modulated LHCD is being evaluated. Calculations with a LHCD model in the TSC code have shown that a $10 \mathrm{MW} \mathrm{5.6} \mathrm{GHz} \mathrm{system} \mathrm{with} \mathrm{50/50}$ on/off modulation should be capable of suppressing the $\mathrm{m} / \mathrm{n}=3 / 2$ mode up to $\beta_{\mathrm{N}} \approx 2.0$.

\section{Potential Advanced Tokamak Regimes in FIRE}

The standard regime in FIRE without wall stabilization is limited by kink instabilities to $\beta_{\mathrm{N}}$ $<3$ and bootstrap factions, $\mathrm{f}_{\mathrm{bs}} \leq 50 \%$. Exploitation of advanced tokamak regimes requires stabilization of the low $\mathrm{n}$ kinks as recently demonstrated on DIII-D [3]. If the $\mathrm{n}=1 \mathrm{kink}$ could be stabilized by a conducting wall or feedback in FIRE, then advanced tokamak regimes with $\beta_{\mathrm{N}} \leq 3.6$ and $\mathrm{f}_{\mathrm{bs}} \leq 75 \%$ are possible. TSC has been used to determine the current drive, plasma heating power and energy confinement required to dynamically access these advanced regimes in a burning plasma. The example shown in Fig. 4 has $\mathrm{B}=8.5 \mathrm{~T}, \mathrm{I}_{\mathrm{p}}=5.5 \mathrm{MA}$, which confines alphas very well, and the coils would allow burn times up to $35 \mathrm{~s}$. LHCD is calculated self-consistently using LSC for density profiles

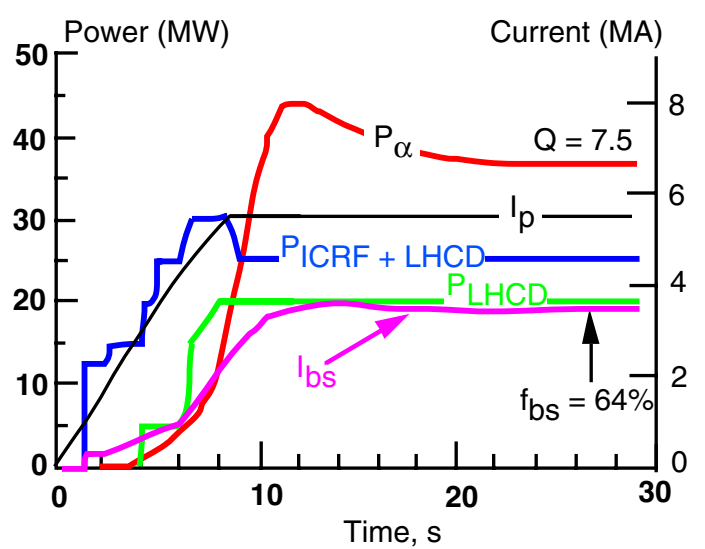

Fig. 4 Advanced Mode in FIRE with $\mathrm{n}(0) /<\mathrm{n}>\approx 1.5$. This quasi-steady reversed shear discharge attained $\beta_{\mathrm{N}}=3.0, \mathrm{f}_{\mathrm{bs}}=64 \%$ and $\mathrm{Q}=7.5$ for moderately enhanced confinement of $\mathrm{H}(\mathrm{y}, 2)=1.6$, and was $100 \%$ noninductively driven after $11 \mathrm{~s}$. Exploitation of these regimes will require stabilization of the $\mathrm{n}$ $=1$, either by feedback from coils mounted in the first wall of the FIRE vacuum vessel or by a method to rotate the FIRE plasma, and improved long pulse capability for the FIRE internal components.

\section{Technology Considerations}

The FIRE engineering characteristics have been described previously $[1,2,4]$. The primary limit on pulse length in FIRE is not the coil system but the capability of the plasma facing components (PFC) to withstand power densities approaching those anticipated in a fusion reactor. FIRE has chosen reactor relevant all metal PFCs; tungsten brush divertor plates and Be tile first wall tiles[5]. This appears to be sufficient for $25 \mathrm{~s}$ pulses at $\mathrm{Q} \sim 10$ and $\mathrm{P}_{\mathrm{f}} \approx 150$ MW. Exploration of longer pulse AT modes will require improvements in the design and/or materials. Analysis of plasma disruptions and VDEs has been conducted, and the induced currents in the vacuum vessel and plasma facing components were computed using the PCOpera ${ }^{\circledR}$ code. The computed currents and forces on the PFCs may allow the use of stainless steel instead of Inconel for the PFC structures.

The FIRE design study is a U. S. national activity managed through the Virtual Laboratory for Technology. PPPL work supported by DOE Contract \# DE-AC02-76CHO3073.

\section{References}

[1] D. M. Meade, et al, $18^{\text {th }}$ IAEA Fusion Energy Conference, Sorrento, 2000

[2] D. M. Meade, et al, 14 ${ }^{\text {th }}$ ANS Topical Meeting on Tech. of Fusion Energy, 2000.

[3] L. C. Johnson, et al, paper P4.008, $28^{\text {th }}$ EPS Conf. on Cont. Fusion and Plasma Physics

[4] R. J. Thome, et al, $21^{\text {st }}$ Symp. on Fusion Technology, Madrid, 2000

[5] M. A. Ulrickson, et al, $21^{\text {st }}$ Symp. on Fusion Technology, Madrid, 2000 


\section{External Distribution}

Plasma Research Laboratory, Australian National University, Australia

Professor I.R. J ones, Flinders University, Australia

Professor J oão Canalle, Instituto de Fisica DEQ/IF - UERJ , Brazil

Mr. Gerson O. Ludwig, Instituto Nacional de Pesquisas, Brazil

Dr. P.H. Sakanaka, Instituto Fisica, Brazil

The Librarian, Culham Laboratory, England

Library, R61, Rutherford Appleton Laboratory, England

Mrs. S.A. Hutchinson, JET Library, England

Professor M.N. Bussac, Ecole Polytechnique, France

Librarian, Max-Planck-Institut für Plasmaphysik, Germany

J olan Moldvai, Reports Library, MTA KFKI-ATKI, Hungary

Dr. P. Kaw, Institute for Plasma Research, India

Ms. P.J . Pathak, Librarian, Insitute for Plasma Research, India

Ms. Clelia De Palo, Associazione EURATOM-ENEA, I taly

Dr. G. Grosso, Instituto di Fisica del Plasma, Italy

Librarian, Naka Fusion Research Establishment, J AERI, J apan

Library, Plasma Physics Laboratory, Kyoto University, J apan

Research Information Center, National Institute for Fusion Science, J apan

Dr. O. Mitarai, Kyushu Tokai University, J apan

Library, Academia Sinica, Institute of Plasma Physics, People's Republic of China

Shih-Tung Tsai, Institute of Physics, Chinese Academy of Sciences, People's Republic of China

Dr. S. Mirnov, TRINITI, Troitsk, Russian Federation, Russia

Dr. V.S. Strelkov, Kurchatov Institute, Russian Federation, Russia

Professor Peter Lukac, Katedra Fyziky Plazmy MFF UK, Mlynska dolina F-2, Komenskeho Univerzita, SK-842 15 Bratislava, Slovakia

Dr. G.S. Lee, Korea Basic Science Institute, South Korea

Mr. Dennis Bruggink, Fusion Library, University of Wisconsin, USA

Institute for Plasma Research, University of Maryland, USA

Librarian, Fusion Energy Division, Oak Ridge National Laboratory, USA

Librarian, Institute of Fusion Studies, University of Texas, USA

Librarian, Magnetic Fusion Program, Lawrence Livermore National Laboratory, USA

Library, General Atomics, USA

Plasma Physics Group, Fusion Energy Research Program, University of California at San Diego, USA

Plasma Physics Library, Columbia University, USA

Alkesh Punjabi, Center for Fusion Research and Training, Hampton University, USA

Dr. W.M. Stacey, Fusion Research Center, Georgia Institute of Technology, USA

Dr. J ohn Willis, U.S. Department of Energy, Office of Fusion Energy Sciences, USA

Mr. Paul H. Wright, Indianapolis, Indiana, USA 
The Princeton Plasma Physics Laboratory is operated by Princeton University under contract with the U.S. Department of Energy.

\author{
Information Services \\ Princeton Plasma Physics Laboratory \\ P.O. Box 451 \\ Princeton, NJ 08543
}

Phone: 609-243-2750

Fax: 609-243-2751

e-mail: pppl_info@pppl.gov

Internet Address: http://www.pppl.gov 